\title{
Student Preference of a Customized, Open-Access Multi-touch Digital Textbook in a Graduate Education Course
}

\author{
Michael S. Mills \\ University of Central Arkansas, United States
}

\begin{abstract}
The purpose of this article is to add to the collective body of research regarding the use of digital books (or eTexts) and their preference by students in higher education. Although there have been many studies in this area, the findings are not necessarily consistent. One reason for this inconsistency is the rapid evolution of e-reading capabilities through recent advances in tablet computing. No empirical studies currently exist to describe the impact of multi-touch interactive eTexts, which are only accessible on these latest tablet computers. The purpose of this study was to determine how graduate pre-service teacher education students perceive the interactivity, engagement, and value of customized course eTexts. Participants in this quasi-experimental study rated the level of interactivity, engagement, and value of three eText formats: page fidelity (Adobe PDF), reflowable text (Kindle ePub), and multi-touch (Apple iBooks). Users of the multi-touch eText reported a significantly more interactive and engaging experience with their text than the other eText users. The experiment also revealed that students overwhelmingly prefer a free, customized openaccess text for use in their course, no matter what eText format is used.
\end{abstract}

Keywords: e-book; Multi-touch; Digital textbook; eText; Tablet computers

\section{Introduction}

With the rapid increase in the number of mobile devices in society (particularly in higher education), the prominence of electronic books has steadily risen. A clear example of this is the dominance of electronic book sales over printed book sales by online bookseller Amazon due to its Kindle e-reader (Miller \& Bosman, 2011). Beyond the Kindle, the rising popularity of tablet computing has the potential to greatly impact electronic texts and other digital resources in higher education learning. As noted in the 2015 Horizon Report for Higher Education, tablet computing has captured the attention of educators and students because of the ability to consume, curate, create, and share virtually anything from virtually anywhere. Tablet computers, such as the Apple iPad, the Amazon Kindle Fire or the various Android-based tablets like the Nexus, have the capability to become portable learning environments that connect students to each other, their teachers, and other experts in their field of study.

Because of this increase in the number and versatility of tablet computers and their ability to function as e-readers, eTexts are becoming more frequently used in higher education courses. The trend seems to be long-term, as the percentage of adults who have read an electronic text has risen 
to $28 \%$, increasing five points from 2013 (Zickuhr \& Rainie, 2014). Looking forward, this trend extends to the younger generation, the college students of tomorrow, as the percentage of 12-17 year olds who have read an electronic text has nearly doubled since 2010 from $25 \%$ to currently $46 \%$ (Scholastic 2013). Additionally, the number of those owning a tablet computer or dedicated ereader device has increased over the past several years, with 35\% owning a tablet computer and $24 \%$ owning a dedicated e-reader device (Rainie \& Smith, 2013), and the number of those preferring eTexts seems to be on the rise (Scholastic, 2013).

Textbooks function as a dominant influence for faculty and students in the higher education classroom, and in recent years have begun to appear more in digital formats, sometimes referred to as electronic textbooks or e-textbooks (McFadden 2012). Digital textbooks are formatted texts that can be read on a computer or mobile device, such as a laptop, smartphone, or tablet computer. There is no real consensus on what term to use when referring to digital textbooks used in education. While some opt for "eBooks" (Richardson \& Mahmood, 2012) or "e-books" (Woody et al., 2010), others use the term "e-texts" (Stoop, et al., 2013) or "eTexts" (Schugar et al., 2011). As this study is focused specifically on the use of textbooks in digital format, this study will rely on Baron's (2015) suggestion that "eText" is the most appropriate generic term for digital textbooks. All eTexts are not created or accessed in the same way. Specifically, the three eText formats presented to participants in this study were multi-touch interactive (with the file extension ibooks or .iba), interactive PDF (with the file extension .pdf), and a proprietary ePub format (with the file extension .kf8) used in the Kindle.

\section{Benefits and Drawbacks to eTexts}

There are many considerations when considering using eTexts in a higher education classroom, yet the research on eText usage in higher education has been decidedly mixed. Much of the extant research focuses on the negative aspects of eTexts. Citing numerous studies, Ackerman and Goldsmith (2011) indicate students have a general preference for print-reading from paper over reading from electronic displays. Some other reported drawbacks of eTexts include increased fatigue and discomfort from screen reading (Clark et al., 2008; Gunter, 2005; Jeong, 2012; Kang et al., 2009; Nicholas et al., 2010), relative expense in purchasing a mobile device or e-book reader, and overall difficulty in sharing, text highlighting, and note taking (Knutson \& Fowler, 2009). Other researchers have gone so far as to denounce eTexts as a non-viable medium altogether (Daniel \& Woody, 2012; Woody et al., 2010).

As critical as these studies are, some of the benefits of eTexts reported in other studies include convenience and portability (Ashcroft \& Watts, 2004; Clark, 2009; Kang et al., 2009; Kimball et al., 2010; Pattuelli \& Rabina, 2010), currency of information (Shelburne, 2009), and the ability to search text easily and store multiple titles on one device (Armstrong et al., 2009; Siegenthaler et al., 2012). Other possible benefits might include text-to-speech capability, online dictionary access, and social media sharing (Smith \& Kukulska-Hulme, 2012). Further, a specific potential academic benefit of eTexts includes a higher likelihood that students will use cognitive and self-regulation strategies than students who use traditional print textbooks (Rockinson-Szapkiw et al., 2013). 
In light of these findings, there is increasing evidence that certain types of eTexts used under certain conditions offer inherent advantages over print textbooks (Taylor 2011). In fact, the concerns raised in the extant literature may be mitigated by the multi-touch capability of tablets released since 2011, including the second generation Apple iPad and various Android-based tablet devices. The capability of these devices to support multi-touch interactivity has expanded the potential for student engagement and has allowed a deeper look into what potential these digital texts may have. Siegenthaler (2012) singled out Apple's iPad as a superior reading device for non-linear reading compared to its e-ink counterparts (e.g., Amazon's Kindle) due to its enhanced navigational features and screen sensitivity.

As Woody, Daniel, and Baker (2010) note, the full capability of eTexts has yet to be fully studied. Many of the studies articulating a preference for print over digitally formatted texts were published before multi-touch or high-density pixel displays were common features in mobile technology, and all featured students using conventional eTexts, that is, PDF replicas of the printed text or reflowable text with limited interactivity (i.e., only Internet hyperlinks) on a desktop or laptop computer. The displays and interfaces used in these studies (notably Ackerman \& Goldsmith, 2011; Annand, 2008; Eshet-Alkalai \& Geri, 2007; Rogers, 2006; Shaikh, 2004; Spencer, 2006) hardly represent current technology, particularly since multi-touch books on high resolution mobile screens have only been available since the second generation of the iPad tablet computer was introduced in 2011. As such, many of these earlier studies do not take into account the inherent benefits of powerful tablet computers capable of multi-touch eTexts that feature dimensional navigational structures and rich interface capabilities, notably a reader's interaction with interactive widgets, dynamic annotation, social media integration, and embedded audio and video. Noting the limitations of the studies that were conducted before the introduction of advanced multi-touch tablet computers in 2011 because the studies that did not feature a multi-touch tablet as an e-reader, we must consider how this new generation of portable devices reframes our consideration of eTexts as a viable resource in education.

\section{Conventional and Multi-touch eText Formats}

eTexts can be accessed through at least three major formats: page fidelity, reflowable text, and multi-touch interactive (Fenwick et al., 2013; Rockinson- Szapkiw et al., 2013). Page fidelity texts are simply facsimiles of the printed text, either as scanned images or PDF files. Each page of text is meant to look just as it would as printed text, no matter what device is used to access the text. One potential disadvantage of this format is the considerable hardship on readers using mobile devices with smaller screens. Reflowable texts, on the other hand, adjust their format based on what device is being used to access the text and even how the device is being held. Multi-touch interactive texts are characterized by reflowable text and contain a combination of embedded audio, video, and interactive images and widgets. Widgets are HTML-based components that allow readers to interact through pinching, tapping, and swiping the screen on the e-reader device. Widgets include playable presentation decks, 3D models, zoomable images, image galleries, scrollable text, pop-over text, and interactive assessments, all of which can enhance a digital text to include what otherwise might span several separate volumes and supplementary material accessed through external means (Wright 2014). 
Whereas the research base for determining the value of eTexts in higher education is growing, what is nonexistent is empirical research incorporating multi-touch interactive eTexts. This is troubling because multi-touch interactive eTexts have dynamic and interactive features that other eText formats do not, which may be a defining factor in eText acceptance, efficacy, and widespread implementation as a digital textbook format.

Renninger et al. (1992) suggest academic engagement may be increased through situational interest, which can be stimulated by specific interactive objects embedded in the learning environment or in instructional resources for the express purpose of promoting interest from a specific situation. Thus, multi-touch interactive eTexts may provide a means by which situational interest can be stimulated because of their inclusion of customized, dynamic content and rich interactivity. Furthermore, the dual-coding that is prevalent in image-based texts may be expanded to a triple-coding by which the interactive, multimodal features of a multi-touch interactive eText can stimulate not only audio and visual processing but also kinetic processing (Large et al., 1994; Low \& Sweller, 2005; Mayer, 1997, 2001, 2005; Moreno, 2006; Moreno \& Mayer, 1999, 2002, 2007; Paivio, 1986). Mbarika et al. (2010) add that the interactive features that are of most value are those that bring real-world issues into the classroom, a point employed in the multi-touch digital textbook employed in this study.

The most commonly used eText formats in recent years include reflowable text (ePub, AZW (Amazon Kindle), and HTML) and page fidelity text (PDF), all of which can be accessed on a variety of mobile and desktop devices. In fact, any author can create an eText using one of these formats, and that is the route most publishing companies have taken. Unfortunately, for most of these formats, the author or designer cannot know for certain which device will be used to access the information, which results in an uneven experience for users. In other words, the layout or an interactive feature may change significantly depending on which device the material is being accessed. In addition, there is not a dimensional navigational structure or widespread inclusion of embedded media and interactive elements in these formats.

The exceptions are the iBooks format (accessible only through an iPhone and iPod Touch running iOS 8.4 or later, second-generation iPads and later, and Macs running Mac OS X 10.9 or later), and the .kf8 Kindle format (accessible only through an Amazon-approved device (Kindle Fire) or the Kindle mobile application). However, there remains a significant difference between Amazon's basic e-readers, which can display .azw files using e-ink technology, and its multi-touch tablets like the Kindle Fire series, which can display rich multimedia and interactive content using the .kf8 file format. One significant difference is that the basic e-ink readers cannot display color images, feature embedded video, run apps, or utilize a dimensional navigational structure. Thus, the functionality of an interactive textbook that might utilize some of these features would not be available across all Kindle devices. A significant drawback of the .kf8 file format, the more advanced interactive multimedia Kindle e-book format, is that there is no sense of dimensional navigational structure and, importantly, a mainstream .kf8 authoring tool available. The lack of such a tool makes it less possible that the current generation of Kindle Fires could help deliver multi-touch interactive open access resources.

It is for this reason, this study's focus is limited to a specific eText format that can be standardized and can offer a consistent experience to both readers and creators of digital textbooks. In 2011, 
Apple began offering the free iBooks Author software application, which allows anyone with a Mac (OSX 10.9 or later) computer to create multi-touch interactive eTexts. Apple highlighted, in particular, the capabilities of this software to create highly interactive digital textbooks. Thus, faculty (and students) now have the capability to create multi-touch interactive digital textbooks that incorporate a variety of interactive tools beyond the limited interaction offered in traditional eTexts.

\section{eText Topography}

Multi-touch interactive textbooks accessed through the iBooks app on the iPad may mitigate many of the concerns past studies have raised concerning eTexts. One complaint of eTexts is that they fail to offer readers sufficient guidance for active reading through contextual clues derived from the physical tangibility of a traditional printed book (Mangen, 2008). As Li et al. (2013) elaborate, readers may not have the sense of where they are in a digital textbook because of the flattened structure of the text, whereas a reader of a printed book can dog-ear or flip the physical pages as a navigational aid. However, cognitive maps, which represent parts of the text as graphical objects, offer a way for readers to see the whole of a text and drill down to the specific area needed when needed. One can think of this dimensional navigational structure like Google Maps, which allows a user to see an entire geographic region and then zoom in all the way to a street level view.

The multi-touch interactive iBooks format structures texts in such a way. Readers can view texts chapter by chapter by swiping a finger left and right on the iPad screen and zoom in by tapping on a particular page, which is represented as a thumbnail image. Readers can zoom back to the chapter by chapter navigational structure by pinching in with two fingers. These navigational aids, along with headings, illustrations, bookmarks, and highlighted text, replicate for readers the physical landscape of a printed book.

\section{Method}

\section{Purpose of the Study}

The purpose of this study was to determine how graduate pre-service teacher education students perceive the interactivity, engagement, and value of customized course eTexts.

A free, custom textbook was created for the purpose of this study and was the required text for a graduate course in classroom management because there did not exist any multi-touch interactive digital textbooks in the content area being taught in the study. The researcher used the Pages, iBooks Author, and Adobe Acrobat X applications to create three versions of the eText. Pages and iBooks Author were used to author the multi-touch eText, which served as the primary resource for the experimental group. The PDF and Kindle versions for the control group were created by converting the static text and images as well as hyperlinks from the Pages application into PDF and Kindle ePub (KF8) formats respectively.

The course eText, in its various forms, incorporated lecture notes and presentations, excerpts from peer-reviewed journals and other periodicals, as well as videos, images, and interactive widgets (i.e., 
photo gallery, review quizzes, zoomable diagrams, embedded animated slide decks) that supported the content specific to the requirements outlined by Clark and Mayer (2011). The content came from a mix of resources obtained through faculty-created resources, the public domain, Creative Commons-licensed material, and copyrighted material used with permission and within the scope of the fair use guidelines of the United States Copyright Act for the purpose of illustration and comment. All of the video and image content was customized according to a design aesthetic that offered ease of use and maximized visual appeal (Mayer \& Moreno, 2003; Moreno \& Mayer, 1999).

\section{Participants}

Participants were 115 graduate students (26 males and 89 females) enrolled in a teacher certification program at a medium-sized mid-Southern regional university in the United States. The majority of the students reported being under 30 years old (62.6\%). Participants were treated in accordance with American Psychological Association (APA, 2009) guidelines.

The study included an experimental group using the multi-touch eText and the control group using a PDF or Kindle version of the text with links to the multimedia content. Each semester, there were two sections of the graduate course offered, and students self-selected into either section, both of which were taught by the same instructor. Students had no knowledge of what format of eText they would be using, only that their course textbook would be free and in a digital format. The experimental and control groups were comprised of each course section and were chosen randomly. The study was replicated over three semesters.

\section{Procedure}

A quasi-experimental design was chosen because of the inherent difficulty of assigning different eText formatted textbooks to random students within the same course sections. To put it more simply, students from each course section needed to use the same eText format, else there would be possible violation of integrity as to who was using a control variable and who was using an experimental variable. Rather, assigning eText formats by course section as a whole, albeit randomly, prevented cross-contamination of the experimental and control groups.

Students in the experimental group were given the link to download the multi-touch interactive digital textbook (iBooks Author version) from Apple's iBooks Store. This method was chosen over disseminating the actual iBooks file because of two reasons: (1) iBookstore versions of multi-touch interactive digital textbooks are compressed in size, and (2) students were able to download the textbook at their leisure, just as the control group was able to download a PDF or Kindle version in the same manner. As the multi-touch iBook format can only be accessed using an iPad Touch (5th Generation or later running iOS 8.4 or later), iPhone (4S or later running iOS 8.4 or later), iPad 2 or higher (iOS 7 or later) or Mac OS X (10.9 or later) computer or higher, students were loaned, at no cost, an iPad Mini for the duration of the course. Notably, the iBooks format was only available on the iPads and Mac OS X computers at the time of the study. 
Students in the control group were given the option of downloading the PDF version of the textbook or securing a version in Amazon Kindle format, both of which contained the same images and hyperlinked resources but contained no embedded videos or multi-touch interactive content. Students still had access to the interactive content and videos through the Blackboard learning management system (LMS) assigned to their class and through hyperlinks provided in the eTexts. These students could access their eTexts on a wide variety of devices through the Kindle app or Adobe Acrobat Reader.

Participants completed a demographics questionnaire and stated their preference of eTexts in general as well as their level of proficiency and preference of technology for accessing multimedia content. Then, participants used a 6 -point scale $(1=$ strongly disagree, $10=$ strongly agree $)$ to indicate their level of comfort with laptops and tablet computers. Next, participants used a 10-point scale ( $1=$ not at all, $10=$ extremely) to rate the level of engagement and interactivity of the eText used for the course and a separate 10-point scale ( 1 = very useless, $10=$ very useful) to indicate the usefulness of various eText features, including annotation, search, and accessibility. Participants also indicated to what degree they used particular devices to access the eText used in their course.

\section{Results}

\section{Engagement and Interactivity of eText Mediums}

Of the 115 participants, 54 (47\%) accessed the course eText as an interactive PDF, four (3.5\%) accessed the course eText as a Kindle KF8 format, and 57 (49.6\%) accessed the course eText as a multi-touch book authored in iBooks Author. The participants in the study reported their perception of interactivity and engagement of eTexts presented in all three mediums (Adobe PDF, Kindle KF8, multi-touch) using a 10-point scale ( $1=$ Not at all, $10=$ Extremely). Means and standard deviations are referenced in Table 1.

Table 1. Means and Standard Deviations of Participants' Perception of Interactivity and Engagement of eText Mediums (i.e., Adobe PDF, Kindle, Multi-touch)

\begin{tabular}{|l|c|c|c|}
\hline & Adobe PDF $(N=54)$ & Kindle KF8 $(N=4)$ & Multi-touch $(N=57)$ \\
\hline Interactivity & $(M=7.2, S D=2.004)$ & $(M=9, S D=1.414)$ & $(M=9.7, S D=.626)$ \\
\hline Engagement & $(M=7.96, S D=1.78)$ & $(M=9.25, S D=1.5)$ & $(M=9.67, S D=.69)$ \\
\hline
\end{tabular}

To account for possible confounding factors, participants were asked to rate their level of proficiency on the devices on which eTexts would be accessed. On a 6-point scale $(1=$ strongly disagree, 6 = strongly agree) participants reported their agreement with the statements, "I am proficient at using desktop or laptop computers" $(M=5.32, S D=.894)$ and, "I am proficient at using a tablet computer (e.g., iPad, Surface, Kindle Fire, or Nexus)" $(M=4.69, S D=1.224)$ and identify the device they used to access the eText (laptop/desktop or tablet computer).

An ANCOVA analysis taking into account participants' self-reports of laptop/desktop and tablet proficiency as well as the devices they used to access the eText revealed a large main effect of eText medium used on both perceptions of text interactivity, $F(6,105)=16.266, p=.001, \eta p 2=.482$, and 
text engagement $F(6,105)=10.034, p=.001, n p 2=.364$. The threshold for effect size (partial eta squared) was increased because of possible confusion with eta squared (Levine \& Hullett, 2002; Pierce et al., 2004).

A post hoc analysis with Bonferroni correction indicated that the mean change score was significant for level of interaction $(M=-1.903, p=.0001)$ and engagement $(M=-1.197, p=.001)$ for users of Adobe PDF eTexts than for users of multi-touch eTexts. The implication is that participants who accessed the Adobe PDF version had a significantly more negative perception regarding the level of interaction and engagement of their medium compared to the participants who rated their perception of interactivity and engagement of the multi-touch version. The device used to access the Adobe PDF version had no effect.

\section{Usefulness of Interactive Elements of eText Mediums}

The participants in the study reported the usefulness of interactive elements of the eTexts presented in all three mediums (Adobe PDF, Kindle KF8, multi-touch). A univariate analysis analysis was conducted to ascertain the usefulness of interactive elements in each of the eText mediums. (Adobe PDF: $M=4.94, S D=1.188, \mathrm{n}=54$; Kindle $=M=5.75, S D=.5, \mathrm{n}=4$; Multi-touch: $M=5.74, S D$ $=.613, \mathrm{n}=57$ ). A post hoc analysis with Bonferroni correction revealed a significant and large main effect of the usefulness of interactive elements in the multi-touch eText compared to the Adobe PDF eText, $F(6,105)=16.266, p=.0001, \eta p 2=.267$. This is not surprising as the interactive elements for the multi-touch eText were embedded within the text itself while the interactive elements for the Adobe PDF and Kindle eTexts were accessed through hyperlinks to a website hosting the multimedia elements.

\section{Perceived Value of eTexts}

Participants were asked to report on the value of the eText they used during the course of the study. On a 10 -point scale ( $1=$ not at all valuable, $10=$ extremely valuable) participants reported their agreement with the statement, "Compared to a traditional professionally published textbook, what was the overall value of the instructor-created digital textbook." Participants overwhelmingly valued the eText they used, no matter the form (Adobe PDF: $M=8.67, S D=1.925, \mathrm{n}=51$; Kindle: $M$ $=10.0, S D=.0001, \mathrm{n}=4$; Multi-touch interactive: $M=9.68, S D=.827, \mathrm{n}=57$ ).

An ANCOVA analysis taking into account participants' self-reports of laptop/desktop and tablet proficiency and device used to access the eText revealed a significant main effect of eText form used on perceptions of value with a large effect size $F(6,105)=3.482, p=.004$, np2 $=.166$, for eText medium used. A post hoc analysis with a Bonferroni correction revealed a mean difference of .648 higher for users of multi-touch eTexts than for Adobe PDF eText users. 


\section{Should Customized eText Resources be Free and be Made Widely Available in Graduate Education Courses?}

Subjects were asked to identify on a scale from one to four ( $1=$ Yes, 2 = Leaning Yes, 3 = Leaning No, $4=\mathrm{No})$ their agreement that customized digital textbooks should be offered in other courses $(96.5 \%$ indicated some level of agreement, $n=115, M=1.37, S D=.582$ ) and agreement on a scale from one to six ( 1 = strongly disagree, 6 = strongly agree) if course textbooks should be freely available even if those resources were not professionally published $(96.5 \%$ indicated some level of agreement, $\mathrm{n}=115, M=5.51, S D=.892$ ).

Multiple ANCOVAs were run and found no significant effect on eText medium used, taking into account participants' reports of how proficient they were in using laptop, desktop, and tablet computing devices and the devices they used to access the eText, on their indication that digital textbooks should be offered in other graduate courses, $F(6,105)=1.244, p=.290, n p 2=.066$, or that digital textbooks should be free and widely available, even if such texts are not professionally published, $F(6,105)=.761, p=.602, n p 2=.042$. These results indicate a strong demand for free digital textbooks in graduate course, no matter the eText format.

\section{Discussion}

This comparison of students' self-reports of interactivity and engagement of eTexts in different mediums revealed several important findings. There were no effects in perception of computer proficiency or the device participants used to access the texts to measures of eText interactivity, engagement, or value found in the current study. There was a clear indication that a multi-touch eText with embedded multimedia was viewed more positively in terms of interactivity, engagement, and value over an Adobe PDF version of the same text with links to media hosted outside the text itself. The Kindle KF8 version was not used by a significant number of students ( $N=4,3.47 \%$ ), casting doubt on the applicability of any results from that version. However, the commonality of the page reflowable text format, like that in multi-touch texts, may account for the preferences of the few students who used that version.

Second, in partial contrast to the findings by Woody et al. (2010), who argued students have an aversion to eTexts, participants in this study demonstrated a high level of desire to have eTexts offered in other graduate courses. Based on the empirical data and several student comments, there was an overwhelming desire of students to access an open-access digital textbook that was customized for the class over a textbook from a traditional publisher. An overwhelming majority of students $(96.5 \%, \mathrm{n}=111)$ value free, customized eTexts even if not distributed by a mainstream book publisher. This confirms McFadden's (2012) contention that cost remains a huge factor in student's textbook purchasing decisions.

It is interesting to note that participants who were given a choice between accessing the digital textbook in Adobe PDF or Kindle format overwhelmingly chose the Adobe PDF format over the Kindle format. Even though both can be accessed on the same devices, the users of the Kindle format generally preferred their text in terms of interactivity, engagement, and value, but not to a significant degree. This should be studied more because the essential difference between the Adobe 
PDF and the Kindle formats is the latter is a reflowable text format, and the former is screen-fidelity. Perhaps participants' opinions centered on this feature. However, there were not enough participants who chose the Kindle format to make such conclusions, and this should be considered a possible limitation of the findings and also a point for further study.

Because of the very strong effect size for levels of engagement, interactivity, and value of multitouch texts over Adobe PDF texts, and the relative ease of authoring such multi-touch texts for classroom use, faculty and staff searching for ways to better engage students with interactive course materials might look to multi-touch authoring tools such as iBooks Author, or if they possess the proficiency, Adobe InDesign CC, to cultivate and present material customized for their courses.

It is encouraging to know that participants in this study viewed digital textbooks in an overwhelmingly positive light, expressing the hope that other course might adopt the use of openaccess customized eTexts. This is a complete turnaround from earlier findings that indicated students prefer print books over eTexts (Woody et al., 2010). An important variable that has developed only recently is the increased portability and multi-touch capabilities of current digital reading devices. The introduction of the second generation iPad and other advanced multi-touch tablet computing devices in 2011 and beyond changed the way students are able to read and interact with eTexts in a deeper way than they could as demonstrated in earlier studies. Whereas in earlier studies, student engagement with an eText was limited to low-resolution eTexts using a laptop or desktop computer in a fixed location, students today can carry their texts as they would any other print text using a high-resolution multi-touch device. This study confirms the value that students have on all open-access eTexts and validates the inclusion of multi-touch interactive elements in eTexts as having a measurable impact on student perceptions of eText engagement and interactivity and value.

\section{Limitations}

It should be noted, as with most other studies, these findings are limited by the size and composition of the sample from which it was based. These findings may not be generalizable to other courses outside the content area covered in this study, nor may they be generalizable to courses that are not designed for non-traditional or graduate level certification purposes. Furthermore, the overwhelming demographic represented in this study were white females under the age of 30 , so applicability to minority populations is still in question.

Other limitations include the restriction of the multi-touch eText format as used in this study to more recent iPad and Mac devices. Because of the difficulty in creating a comparable multi-touch eText in the Adobe InDesign CC application and the absence of a means to create a multi-touch eText using Amazon's Kindle ePub creator, there was not a completely equal footing for all devices. The scope of this study only extends to the preference participants had for the multi-touch eText authored through the iBooks Author application and accessed with an iPad or Mac computer over an Adobe PDF eText or Kindle KF8 format accessed through a variety of tablet computers (including the iPad) and laptop computers.

Generalizing these results must be taken into context within the technology that exists now. Care must be given to recognize the rapidly changing nature of technology, specifically with respect to 
eText formats and the features they may possess in the future. Additionally, the devices used to access eTexts have undergone a dramatic change in the past decade, and it is reasonable to predict future devices may have capabilities not yet considered. At the time of this study, all devices used to access eTexts gave readers the capability to annotate, highlight, look up definitions, convert text to audio, and share notes and excerpts, but at different levels of usability. It is not clear if increases in device functionality might affect perceptions of interactivity and engagement more than the medium as the capabilities of these devices increase.

A further limitation is the main effects of this study were determined by students' self-reports on a questionnaire, which may exclude further understanding of the depth of what constitutes interactivity, engagement, and value. This depth could be explored in further research, particularly with respect to the specific interactive elements that increase students' engagement with an eText and the subsequent value they place on the medium.

What may not necessarily be a limitation in the conventional sense, yet is notable to mention, is that the customized text in this course should not be confused with being an open education resource (OER). At best, the customized textbook can be labeled as open access. Although the multitouch text is available at no cost to anyone with access to the iBooks Store, the alternate PDF and Kindle versions are not widely available. Additionally, the multi-touch text is packaged by the iBooks Store in such a way that it cannot be easily extracted and rendered into different forms. Furthermore, the inclusion of material under a Creative Commons Share Alike license or copyrighted material used under Fair Use guidelines and with permission by the owners does not extend to those who might want to use the same material in another OER. Further study needs to account for the fair and responsible distribution of multi-touch interactive elements as well as the text copy included in open access eTexts.

\section{Further Study}

Noting the value multi-touch eText users was statistically significant in contrast to the value Adobe PDF eText users, one must invariably ask why. Perhaps the reflowable text combined with the dimensional navigational structure of the multi-touch medium offers more to users than the fixedlayout format of PDFs, or maybe multi-touch eTexts offer greater convenience through embedded multimedia and interactive widgets. These discrete features should be studied more in future research to determine the relative impact each interactive element might have.

If the more advanced capabilities of eTexts, including embedded videos and interactive objects, were able to be integrated into Adobe PDFs and Kindle formats, would there be a significant difference among the mediums? Unfortunately, that may not be answered with current constraints on interactive eText authorship. At the time of publication, only the Apple's iBooks Author application (available on Mac devices only) offers a free, user-friendly interface for authoring and publishing of multi-touch eTexts. While InDesign CC, Adobe's flagship page layout application, has the capability for authors to insert interactive elements similar to those available in iBooks Author, the learning curve for InDesign CC is steep, and the application must be purchased as a larger suite of applications (Creative Cloud). Amazon currently does not have a means to author and publish an 
eText that incorporates interactive widgets, but, as of April, 2015, has available a beta version of Kindle Textbook Creator, which allows for embedded audio, video, and pop-up images.

This study validated the idea that, no matter the format of the eText, students believe higher education courses should make available free, open-access customized digital textbooks. Furthermore, the previous research on eText preferences and usability must be re-evaluated in light of recent advances in eText interactive features, authoring options, and mobile device capabilities. Much more research is needed to identify the specific interactive elements that have the most impact on reader engagement as well as the accessibility options of various eText formats to increase access to those with hearing and sight impairments.

There remain significant concerns regarding the ability of faculty to author potentially timeconsuming open access resources, particularly multi-touch formats, which require the cultivation of not only text, images, and audiovisual material but also interactive widgets, the latter of which often involve slide deck animations and HTML programming.

The purpose of this study was not to suggest multi-touch interactive books, or conventional e-books for that matter, should replace print texts. Rather, as students and faculty have indicated that they prefer works to be available in multiple formats (Lindshield \& Adhihari, 2013), the choice should ultimately be theirs. Therefore, as (Garrod 2003) observed, alternative forms of text, such as eTexts, should become one more choice rather than a substitution for all other forms. Regardless of the academic benefits of eTexts, cost remains as a major factor in student adoption of any text, digitally enhanced or not. Virtually every participant in the study, regardless of which format used, agreed that course textbooks should be freely available, even if that meant the textbook was not professionally published. eTexts should be a serious alternative for higher education institutions, and multi-touch eTexts should be included in discussions in which text interactivity and engagement are regarded as important factors for textbook adoption.

\section{References}

Ackerman, R., \& Goldsmith, M. (2011). Metacognitive regulation of text learning: On screen versus on paper. Journal of Experimental Psychology: Applied, 17(1), 18-32. doi:10.1037/a0022086

American Psychological Association. (2009). Publication manual of the American Psychological Association. (6 $6^{\text {th }}$ ed.). Washington, DC: American Psychological Association.

Annand, D. (2008). Learning efficacy and cost-effectiveness of print versus e-book instructional material in an introductory financial accounting course. Journal of Interactive Online Learning, 7(2), 152-164.

Armstrong, K., Nardini, B., McCracken, P., Lugg, R., \& Johnson, K. G. (2009). When did (E)-books become serials? The Serials Librarian, 56(1-4), 129-138. doi:10.1080/03615260802679432

Ashcroft, L., \& Watts, C. (2004). Change implications related to educational resources. Online Information Review, 28(4), 284-291.

Clark, D. T. (2009). Lending Kindle e-book readers: First results from the Texas A\&M university project. Collection Building, 28(4), 146-149. doi:10.1108/01604950910999774 
Clark, D. T., Goodwin, S. P., Samuelson, T., \& Coker, C. (2008). A qualitative assessment of the Kindle e-book reader: Results from initial focus groups. Performance Measurement and Metrics, 9(2), 118-129. doi:10.1108/14678040810906826

Clark, R., \& Mayer, R. (2011). E-learning and the science of instruction: Proven guidelines for consumers and designers of multimedia learning. San Francisco, CA: Wiley.

Daniel, D. B., \& Woody, W. D. (2013). E-textbooks at what cost? Performance and use of electronic v. print texts. Computers \& Education, 62, 18-23. doi:10.1016/j.compedu.2012.10.016

Eshet-Alkalai, Y., \& Geri, N. (2007). Does the medium affect the message? The influence of text representation format on critical thinking. Human Systems Management, 26, 269-279.

Fenwick, J. B., Jr., Kurtz, B. L., Meznar, P., Phillips, R., \& Weidner, A. (2013). Developing a highly interactive ebook for CS instruction. In Proceeding of the 44th ACM technical symposium on computer science education (pp. 135-140). Retrieved from Google Scholar

Garrod, P. (2003). Ebooks in UK libraries: Where are we now? Ariadne, 37, 1-12. Retrieved from http://www.ariadne.ac.uk/issue37/garrod

Gunter, B. (2005). Electronic books: A survey of users in the UK. Emerald Insight, 57(6): 513-522.

Jeong, H. (2012). A comparison of the influence of electronic books and paper books on reading comprehension, eye fatigue, and perception. The Electronic Library, 30(3), 390-408. doi:10.1108/02640471211241663

Johnson, L., Adams Becker, S., Estrada, V., and Freeman, A. (2015). NMC Horizon Report: 2015 Higher Education Edition. Austin, Texas: The New Media Consortium.

Kang, Y., Wang, M., \& Lin, R. (2009). Usability evaluation of e-books. Displays, 30(2), 49-52. doi:10.1016/j.displa.2008.12.002

Kimball, R., Ives, G., \& Jackson, K. (2010). Comparative usage of science e-book and print collections at Texas A\&M university libraries. Collection Management, 35(1), 15-28. doi:10.1080/01462670903386182

Knutson, R. \& Fowler, G. A. (2009). Book smarts? E-texts receive mixed reviews from students. Wall Street Journal, July 16, D1. Retrieved on 16 February 2016 from http://www.wsj. com/articles/SB20001424052970203577304574277041750084938

Large, A., Beheshti, J., Breuleux, A., \& Renaud, A. (1994). Multimedia and comprehension: A cognitive study. Journal of the American Society for Information Science American Society for Information Science, 45(7), 515-528. doi:10.1002/(SICI)10974571(199408)45:7<515::AID-ASI6>3.0.CO;2-3.

Levine, T. R., \& Hullett, C. R. (2002). Eta squared, partial eta squared, and misreporting of effect size in communication research. Human Communication Research, 28(4), 612-625.

Li, L. -Y., Chen, G. -D., \& Yang, S. -J. (2013). Construction of cognitive maps to improve e-book reading and navigation. Computers \& Education, 60(1), 32-39. doi:10.1016/j.compedu. 2012.07.010 
Lindshield, B., \& Adhihari, K. (2013). Online and campus college students like using an open educational resource instead of a traditional textbook. Journal of Online Learning and Teaching, 9(1), 26-37. Retrieved from CrossRef.

Low, R., \& Sweller, J. (2005). The modality principle in multimedia learning. In R. Mayer (Ed.), Cambridge handbook of multimedia learning (pp. 147-158). New York: Cambridge University Press.

Mangen, A. (2008). Hypertext fiction reading: Haptics and immersion. Journal of Research in Reading, 31(4), 404-419. doi:10.1111/j.1467-9817.2008.00380.x

Mayer, R. E. (1997). Multimedia learning: Are we asking the right questions. Educational Psychology Review, 8, 357-371. doi:10.1007/ BF01463939.

Mayer, R. E. (2001). Multimedia learning. New York: Cambridge University Press.

Mayer, R. E. (2005). Principles for managing essential processing multimedia learning: Segmenting, pretraining, and modality principles. In R. E. Mayer (Ed.), Cambridge handbook of multimedia learning (pp. 169-182). New York: Cambridge University Press.

Mayer, R. E., \& Moreno, R. (2003). Nine ways to reduce cognitive load in multimedia learning. Educational Psychologist, 38(1), 43-52.

Mbarika, V., Bagarukayo, E., Shipps, B. P., Hingorani, V., Stokes, S., Kourouma, M., \& Sankar, C. S. (2010). A multi-experimental study on the use of multimedia instructional materials to teach technical subjects. Journal of STEM Education: Innovations \& Research, 11(2).

McFadden, C. (2012). Are textbooks dead? Making sense of the digital transition. Publishing Research Quarterly, 28(2), 93-99. doi:10.1007/s12109-012-9266-3

Miller, C., \& Bosman, J. (2011, May 19). E-books outsell print books at Amazon. New York Times. Retrieved on 16 February 2016 from http://www.nytimes.com/2011/05/20/technology/ 20amazon.html

Moreno, R., \& Mayer, R. E. (1999). Cognitive principles of multimedia learning: The role of modality and contiguity. Journal of Educational Psychology, 91(2), 358.

Paivio, A. (1986). Mental representations: A dual coding approach. Oxford, UK: Oxford University Press.

Rainie, L., \& Smith, A. (2013). 35\% of those ages 16 and older own tablet computers \& $24 \%$ own ebook readers. Retrieved from http://pewinternet.org/Reports/2013/Tablets-andereaders.aspx

Renninger, K. A., Hidi, S., \& Krapp, A. (1992). The role of interest in learning and development. Hillsdale, NJ: Lawrence Erlbaum.

Richardson, J. V. R., \& Mahmood, K. (2012). Ebook readers: User satisfaction and usability issues. Library Hi Tech, 30(1), 170-185. doi:10.1108/07378831211213283

Rockinson- Szapkiw, A. J., Courduff, J., Carter, K., \& Bennett, D. (2013). Electronic versus traditional print textbooks: A comparison study on the influence of university students' learning. Computers \& Education, 63, 259-266. doi:10.1016/j.compedu.2012.11.022 
Rockinson-Szapkiw, A. J., Wendt, J., \& Lunde, R. (2013). Electronic versus print textbooks: The influence of textbook format on university students' self-regulated learning strategies, motivation, and text anxiety. American Journal of Distance Education, 27(3), 179-188. doi:10.1080/08923647.2013.796230

Rogers, M. (2006). Ebooks struggling to find a niche. Library Journal, 131, 25-26.

Scholastic. (2013). Kids \& family reading report. Scholastic.

Schugar, J., Schugar, H., \& Penny, C. (2011). A Nook or a book? Comparing college students' reading comprehension levels, critical reading, and study skills. International Journal of Technology in Teaching and Learning, 7(2), 174-192.

Shaikh, D. (2004). Paper or pixels: What are people reading online? Usability News, 6. Retrieved on 16 February 2016 from http://usabilitynews.org/paper-or-pixels-what-are-people-readingonline/

Shelburne, W. A. (2009). E-book usage in an academic library: User attitudes and behaviors. Library Collections, Acquisitions, \& Technical Services, 33(2/3), 59-72.

Siegenthaler, E., Bochud, Y., Wurtz, P., Schmid, L., \& Bergamin, P. (2012). The effects of touch screen technology on the usability of e-reading devices. Journal of Usability Studies, 7(3), 94-104.

Smith, M., \& Kukulska-Hulme, A. (2012). Building mobile learning capacity in higher education: Ebooks and iPads.

Spencer, C. (2006). Research on learners' preferences for reading from a printed text or from a computer screen. Journal of Distance Education, 21, 33-50.

Stoop, J., Kreutzer, P., \& Kircz, J. (2013). Reading and learning from screens versus print: A study in changing habits, part 1. New Library World, 114(7), 284-300.

Taylor, K. (2011). Students learn equally well from digital as from paperbound texts. Teaching of Psychology, 38(4), 278-281. doi:10.1177/0098628311421330

Woody, W., Daniel, D., \& Baker, C. (2010). E-books or textbooks: Students prefer textbooks. Computers and Education, 55(3) 945-948.

Wright, J. L. (2014). What enhanced e-books can do for scholarly authors. The Chronicle of Higher Education. Retrieved on 16 February 2016 from http://m.chronicle.com/article/WhatEnhanced-E-Books-Can-Do/145969/?utm_source=Publishers+Weekly\&utm_campaign =cd3c80ed4b-UA-15906914-1\&utm_medium=email\&utm_term=0_0bb2959cbbcd3c80ed4b-304631961

Zickuhr, K., \& Rainie, L. (2014). E-Reading rises as device ownership jumps. Retrieved on 16 February 2016 from http://www.pewinternet.org/2014/01/16/e-reading-rises-as-deviceownership-jumps/

Correspondence: Michael S. Mills, Assistant Professor, College of Education, University of Central Arkansas, Conway, Arkansas, United States 